\title{
Polyneuropathy, Organomegaly, Endocrinopathy, Monoclonal Gammopathy and Skin Changes (Poems) Syndrome
}

\author{
I. Milanov and D.Georgiev
}

\begin{abstract}
A patient with a three year history of POEMS syndrome-polyneuropathy, hepatosplenomegaly M-protein, skin changes, optic disc edema, peripheral oedema, pleuritis, lymphadenopathy, and osteosclerotic myeloma is described. The patient had a twenty year history of psoriasis and impotence was the first sign of the disease. The pathophysiology of this multisystem disorder is unknown, although the $\mathrm{M}$-protein is essential. No improvement was found after radiation, chemotherapy and steroid treatment.
\end{abstract}

\begin{abstract}
Résumé: Polyneuropathie, organomégalie, endocrinopathie, gammopathie monoclonale et modifications cutanées: syndrome de poems. Nous décrivons un patient atteint depuis trois ans d'un syndrome de POEMS polyneuropathie, hépatosplénomégalie, proteine $M$, modifications cutanées, et oedème de la papille optique, oedème périphérique, pleurite, lymphadeenopathie et myélome ostéosclérotique. Le patient avait une histoire de psoriasis depuis vingt ans et l'impuissance avait été le premier signe de la maladie. La physiopathologie de cette affection multisystémique est inconnue, bien que la protéine $M$ en soit un élément essentiel. La radiothérapie, la chimiothérapie et les stéroïdes n'ont apporté aucune amélioration.
\end{abstract}

Can. J. Neurol. Sci. 1994; $21: 60-63$

The term "POEMS syndrome" was proposed by Bardwick et al.' and named also Crow-Fukase syndrome by Nakanishi et al.,2 for a rare multisystem disorder with the cardinal manifestation of polyneuropathy $(\mathrm{P})$, organomegaly $(\mathrm{O})$, endocrinopathy (E), monoclonal gammopathy (M) and skin changes (S). However, patients may also have optic disk edema, infiltrative orbitopathy, intracranial hypertension, high cerebrospinal fluid protein level, osteosclerotic bone lesion, lymphadenopathy, peripheral oedema and pleuritis. ${ }^{3-5}$ It is often associated with osteosclerotic myeloma, ${ }^{1}$ but cases without evidence for myeloma have also been reported. ${ }^{6}$ Osteosclerotic myeloma is a rare $(0.5-3 \%)$ variant of multiple myeloma, and polyneuropathy is frequently seen in the former $(50 \%)$ and rarely (3-5\%) in the latter. ${ }^{7-9}$ The pathogenesis of the syndrome has not been explained, but the M-protein may be the crucial factor. ${ }^{2.8}$ Most cases have been reported from Japan, ${ }^{2,6}$ but POEMS occurs in other parts of the world..$^{8.10-13}$

\section{Case Report}

A 39-year-old man gradually became impotent over a one year period. He then developed numbness of the legs, diffuse darkening of the skin and hypertrichosis over 3-months. The numbness of the legs gradually increased and weakness appeared; the arms were involved within 6-months. Chronic diarrhea occurred subsequently. Two years later the patient was bedridden due to limb paresis and he lost a great deal of weight. His history included psoriasis of the skin for twenty years. He had been treated for chronic idiopathic neuropathy in other hospitals for 2 years.

In September 1991, neurological examination revealed absent tendon reflexes, severe weakness and muscle atrophy in distal, and moderate in proximal leg and arm muscles. There was distal hyperpathia, profound loss of all sensory modalities (including position sensation) in both legs, and moderate hypesthesia in the arms. The patient had hepatomegaly ( $2 \mathrm{~cm}$ below the costal margin), diffuse skin hyperpigmentation, hypertrichosis and multiple psoriatic lesions (Figure 1). There was also hyperhidrosis, acrocyanosis, skin thickening with scleroderma like changes and pitting edema in distal parts of both arms and legs. The face was reddish, the fingernails were white. Prominent axillar lymph nodes were noted.

The patient had optic disc edema, 2 diopters bilaterally, with retinal hemorrhages. The visual acuity was normal and pupillary reactions were preserved.

The EMG findings confirmed the presence of sensorimotor polyneuropathy. No compound motor evoked potentials were elicited after electrostimulation of the peroneal and tibial nerves. The median and ulnar motor nerve conduction velocities ( 24 and $28 \mathrm{~m} / \mathrm{s}$, respectively) were decreased and the amplitudes of the compound motor evoked potentials were also decreased. Sensory evoked potentials were not obtainable in any nerve. No muscle activity was obtainable from the distal muscles of the lower limbs, while evidence of muscle denervation (fibrillation

From the University Hospital IV kilometer, III Neurological Clinic, Sofia.

RECEIVED MARCH 11, 1993. ACCEPTED IN FINAL FORM SEPTEMBER 3, 1993.

Reprint requests to: Ivan Milanov, MD, PhD. Medical University Hospital-JV kilometer, III Neurological Clinic, Blvd. Tzarigradsko shosse - IV kilometer, Sofia 1113 , Bulgaria. 


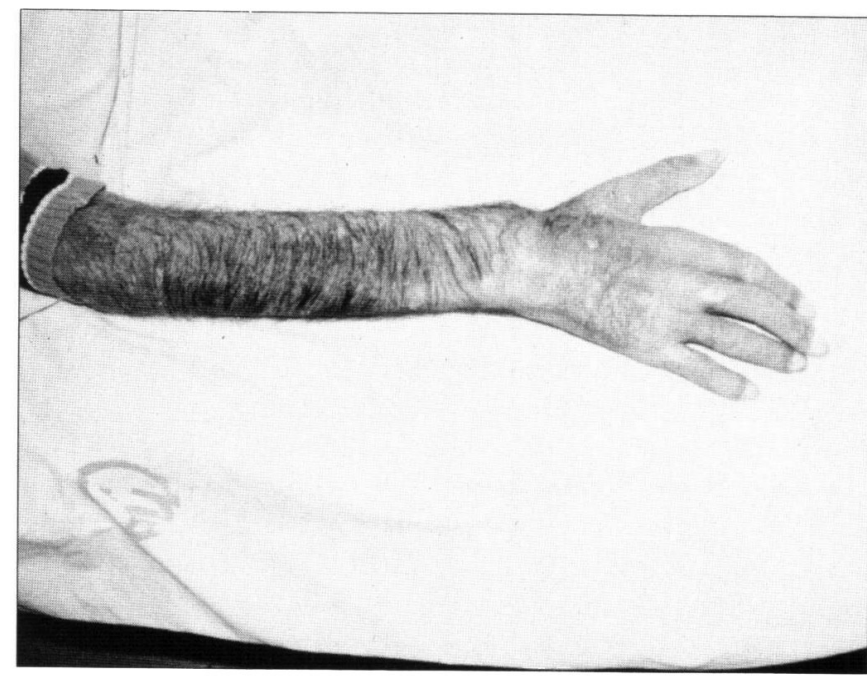

Figure 1: Diffuse hypertrychosis and hyperpigmentation, white fingernails.

potentials and sharp positive waves) was found in the upper limbs. Thus the EMG investigation revealed severe polyneuropathy in lower and moderate in upper limbs with both axonal degeneration and demyelination, confirmed by muscle and nerve biopsy.

Laboratory examination revealed normal haemoglobin, red and white blood cells, platelet and differential count, and erythrocyte sedimentation rate, liver and kidney function tests-SGOT, SGPT, LDH, CPK, GGPT, DFA, cholesterol, triglycerides, alkaline and acid phosphatase, BUN, creatinine and serum electrolytes. Blood glucose was normal, but the glucose tolerance was abnormal. The serum cortisol $(8.8 \mathrm{mcg} \%)$ and estradiol $(21.4 \mathrm{pg} / \mathrm{ml})$ levels were normal, while testosterone $(0.19 \mathrm{ng} / \mathrm{ml})$ level was decreased. There was evidence of hypothyroidism (decreased T3-1.0 nmol/l), while T4 $(93 \mathrm{nmol} / \mathrm{l})$ was within normal limits. The serum protein was $61 \mathrm{~g} / \mathrm{l}$ with normal electrophoresis, but immunoelectrophoresis revealed a small peak of monoclonal IgG lambda paraprotein. Serum and CSF VDRL tests were negative. The Schilling test showed normal absorption of vitamin B12. Antinuclear antibody was normal. Immunoelectrophoresis of the urine revealed monoclonal IgG lambda paraprotein, but no Bence-Jones proteinuria. A porphyrin screen was negative. Bone marrow biopsy examination was normal.

The CSF pressure was not measured. The total CSF protein was greatly increased $(4.04 \mathrm{~g} / 1)$, without pleocytosis. Immunoelectrophoresis of CSF revealed monoclonal IgG lambda paraprotein.

Ultrasonographic examination of the abdomen revealed an enlarged liver and spleen. Endoscopy showed chronic esophagitis, without any abnormalities of the stomach, duodenum, intestines or rectum. Radiography of the gastrointestinal tract revealed no abnormalities. Small intestine biopsy showed partial atrophy of the fila system. The chronic diarrhea was considered to be caused by autonomic neuropathy.

Radiographic examination of the spine found multiple mixed osteosclerotic and lytic lesions at C3 (Figure 2) and S1, confirmed by CT (Figure 3). A myelogram was normal. The CT of brain and radiographic examination of sella turcica showed no abnormalities.

In an open bone biopsy specimen from $\mathrm{C} 3$ and S1 vertebra, osteosclerosis and lymphoplasmacytic infiltrations were found, considered to be osteosclerotic myeloma (Figure 4). Lymph node biopsy showed only chronic inflammation.

The patient was treated with localized radiotherapy, steroids and chemotherapy (Alkeran) without clinical improvement. One year latter his limb paresis had progressed and was severe in the upper as well as in the lower limbs. Clubbing of the fingers was evident. Shortness of breath and paroxysmal nocturnal dyspnea appeared and there was clinical and radiological evidence of pleural and pericardial effusions with heart enlargement. An ECG was normal. No changes were found in the CSF protein and paraprotein levels, nor in the degree of optic disc edema after treatment. The hepatosplenomegaly and endocrinopathy persisted. Enlargement of lytic lesions in $\mathrm{C} 3$ and $\mathrm{SI}$ was found on CT.

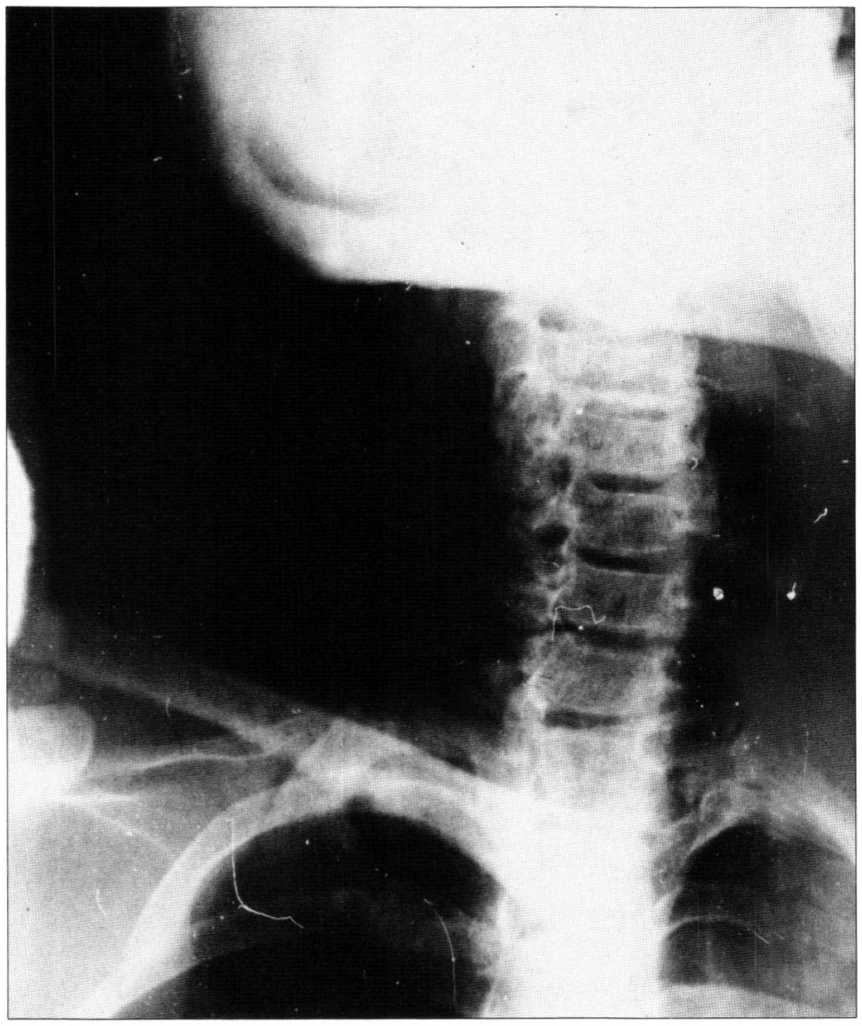

Figure 2: Radiography showing mainly osteosclerotic lesions of C3.

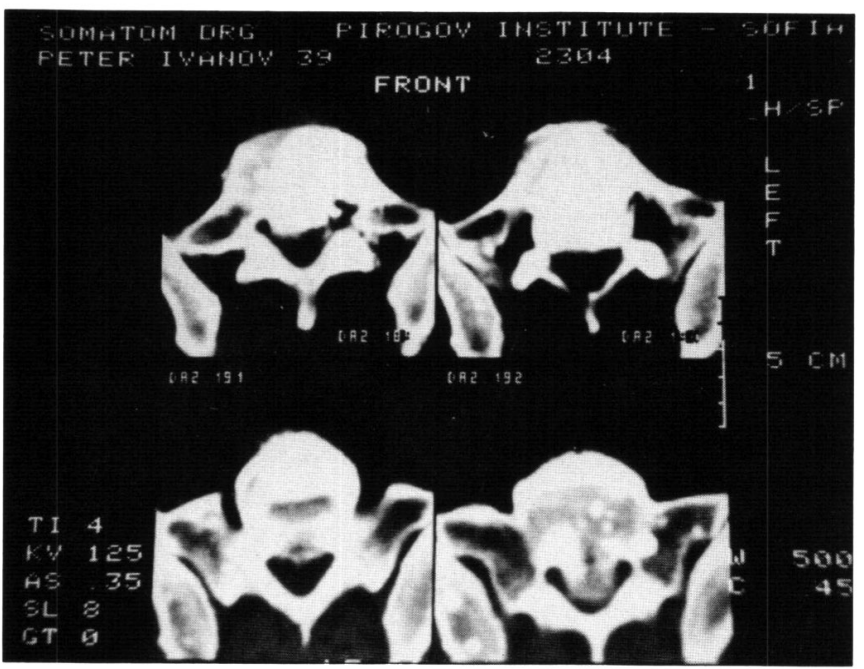

Figure 3: CT with mixed sclerotic and lytic lesions of SI

Some dark reddish verrucous pea-size eruptions appeared over the chest, abdomen and back.

\section{Discussion}

The case presented here had all of the main features of POEMS syndrome-polyneuropathy, hepatosplenomegaly, endocrinopathy, monoclonal IgG lambda gammopathy, skin changes and osteosclerotic myeloma.

Most of the clinical signs in our patient have been previously described in POEMS syndrome, but, we are not aware of reports of any patient with such a completely developed syndrome. 


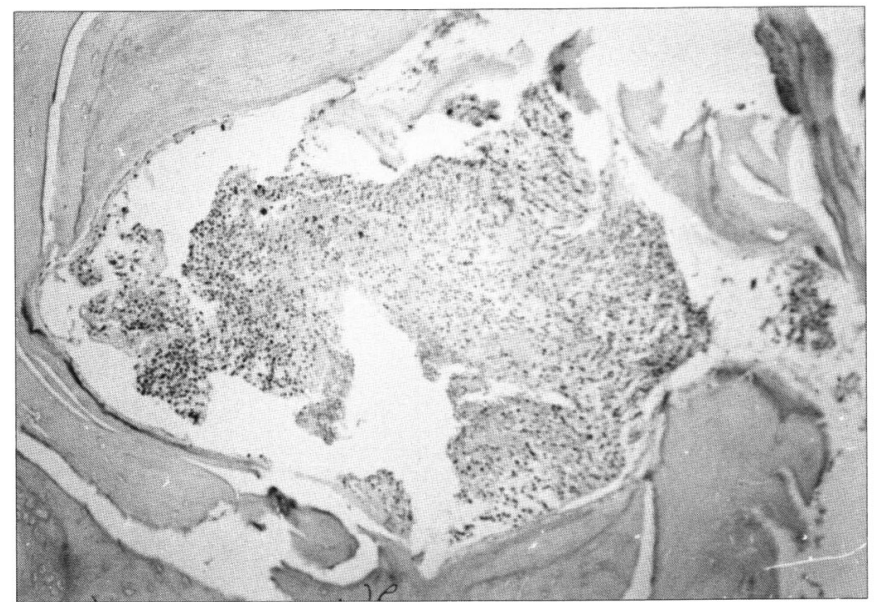

Figure 4: Open bone biopsy specimen from S1-osteosclerosis and lymphoplasmacytic infiltrations. Stain-hematoxylin-eosin, magnification1400 .

Polyneuropathy is reported to be the most consistent and disabling manifestation of the syndrome. ${ }^{1,2.8}$ Usually there is evidence for both demyelination and axonal degeneration. ${ }^{8}$ The neuropathy resembles a chronic inflammatory demyelinating neuropathy and is different from that of patients with typical multiple myeloma. ${ }^{7.8}$ It has a slowly progressive course and weakness is more severe than sensory loss. ${ }^{8}$ In our patient it was extremely severe, probably because of the long course of the disease. No direct correlation has been found between the severity of polyneuropathy and the levels of M-protein. ${ }^{14}$ The autonomic nerves are supposed to be seldom involved, ${ }^{7,8.11}$ but our patient had evidence of autonomic involvement in the form of impotence and chronic diarrhea. The reason for the polyneuropathy is not clear. Polyneuropathy may be a result of immune complex deposits after antibody reaction to the circulating M-protein. ${ }^{12}$ There is evidence for a pathogenetic role of monoclonal paraprotein in demyelination promoted by deposition of myelin-bound antibodies and breakdown of the blood-nerve barrier. ${ }^{15}$ The nerve injury may be mediated by complement. ${ }^{16}$ Increased serum estrogen levels may produce vascular proliferations. ${ }^{6}$ However no deposits of immunoglobulins nor amyloid in nerves, no signs of vasculopathy and no antineuronal or antiglial activity of the monoclonal protein have been found. ${ }^{1,2.5}$ Possibly, the proliferating plasma cells secrete a substance toxic to peripheral nerves. ${ }^{7.8}$ It has been suggested, that the hypothyroidism which is often present may cause the polyneuropathy. ${ }^{17}$

Organomegaly (hepatosplenomegaly) and lymphadenopathy are reported in most of the patients, although their pathogenesis is not clear.'

Endocrine abnormalities have been reported in about $80 \%$ of patients. ${ }^{1.2}$ Most often these have consisted of glucose intolerance or gonadal failure,' but thyroid dysfunction, adrenal insufficiency, and low plasma testosterone concentration have also been observed..$^{5.13}$ The estrogen levels are usually elevated and an accelerated conversion of androgen to estrogen has been found. ${ }^{18}$ Our patient had abnormal glucose tolerance, decreased thyroid function and decreased testosterone levels with impotence, the first sign of the disease, which had persisted for one year without any other signs. The endocrine abnormalities are secondary to inadequate secretion of the trophic hormones by the pituitary gland..$^{7.8}$ It has been supposed, that the IgG lambda protein could react with pituitary gland tissue, so that the pituitary-hypophyseo-hypothalamic complex might be the primary target for pathogenic myeloma antibodies. ${ }^{17}$ This may be the reason for the endocrinopathy and skin changes. The immunopathogenetic lesion of the hypophysis could also induce secondary disturbances of other organs, thus explaining the multisystem disorder. ${ }^{17}$

The etiology of the syndrome is usually supposed to be single or multiple osteosclerotic myeloma, and its pathogenesis somehow connected with the paraprotein. The relation between the POEMS syndrome and osteosclerotic myeloma is uncertain. ${ }^{14}$ The plasma cell dyscrasia is essential, but the link with the manifestations of the disease is unknown. ${ }^{11}$ It is possibly that autoimmune mechanisms are involved. ${ }^{12}$ The proliferated plasma cells in myelomatosis belong to the same clone and produce uniform immune protein named $M$-protein. ${ }^{12}$ Paraprotein of IgG or IgA and rarely of IgM type is nearly always presented in small amount. "In most cases the light chain is of the lambda type. "However, not all patients have a demonstrable monoclonal protein, ${ }^{1.5 .8}$ and cases of the syndrome have been found without myeloma. ${ }^{6}$

The classical radiological bone lesions are mainly sclerotic or sclerotic and lytic. 5.11 .12 The sclerosis may be uniformly dense focus within the bone or with lytic rim surrounding the lesion. ${ }^{5}$ The lytic lesions are usually well-defined and sometimes large. 5.12

Skin changes consist of diffuse hyperpigmentation, skin thickening, reddish face, white nails, finger clubbing and hypertrychosis, ${ }^{13.19}$ which were also present in our patient. Cutaneous angiomas have also been described. ${ }^{13.20 .21}$ The pathogenesis of these changes is unknown. ${ }^{17,20}$ The increased estrogen levels may be responsible for hyperpigmentation and cutaneous angiomas. ${ }^{20,21}$ It is interesting that our patient had normal estrogen levels, despite his skin changes. The long-lasting psoriasis in our patient was reported earlier in one patient. " It is not clear if it had any connection with the myeloma.

Optic disc edema is often found as an initial sign of the syndrome and most patients have intracranial hypertension, but it is not obligatory in diagnosis. ${ }^{3}$ In our patient the optic disc edema was prominent and the CSF protein was extremely high. However it is not clear whether this, or infiltration of the optic nerve with lymphoid cells is the reason for the optic disc edema. ${ }^{3,11}$ Optic disc edema has been found without evidence of elevated intracranial pressure or increased CSF protein. ${ }^{14.22}$

Treatment with localized radiotherapy, surgical extirpation, long-term chemotherapy and steroids is reported to be effective. 1.2.8.14 Our patient had no such improvement, perhaps because of the presence of multiple plasmacytomas or the protracted course of the disease. No correlation has been found between the number of bone lesions and the clinical course of the disease. ${ }^{14}$ Usually patients with single lesion are treated with local irradiation followed by chemotherapy or steroid therapy. ${ }^{14}$ In patients with multiple lesions the response is poor compared to that in patients with single ones. ${ }^{3.8}$ In such cases chemotherapy and steroid therapy may be beneficial, ${ }^{3.8}$ but not localized radiotherapy or surgical extirpation. ${ }^{8.11}$ Most patients have a relapse after the corticosteroid therapy is discontinued, or the high doses are decreased. 8.11 After an initial improvement by chemotherapy a relapse follows and the patients become resistant to further chemotherapy, ${ }^{8.11}$ and despite therapy, most 
patients show slow progression of the polyneuropathy. ${ }^{14}$ Periods of recovery may occur without any treatment, ${ }^{12}$ but no spontaneous improvement has been reported. ${ }^{14}$ In our patient plasmapheresis was not used. It has been reported to be beneficial, ${ }^{11.23}$ or without effect. ${ }^{14}$ Mean survival of reported patients ranges from 22 months ${ }^{7}$ to 33 months. ${ }^{\prime \prime}$

\section{REFERENCES}

1. Bardwick PA, Zvaifler NJ, Gill GN, et al. Plasma cell dyscrasia with polyneuropathy, organomegaly, endocrinopathy, $M$ protein, and skin changes - the POEMS syndrome: report on cases and a review of the literature. Medicine 1980; 59: 311-322.

2. Nakanishi T, Sobue I, Toyokura Y, et al. The Crow-Fukase syndrome: a study of 102 cases in Japan. Neurology 1984; 34: 712720 .

3. Bolling JP, Brazis PW. Optic disk swelling with peripheral neuropathy, organomegaly, endocrinopathy, monoclonal gammopathy, and skin changes (POEMS syndrome). Am J Ophthalmol 1990; 109: 503-510.

4. Bourdette DN, Rosenberg NL. Infiltrative orbitopathy, optic disk edema, and POEMS. Neurology (Clev) 1984; 34: 532-533.

5. Resnick D, Greenway GD, Bardwick PA, et al. Plasma cell dyscrasia with polyneuropathy, organomegaly, endocrinopathy, m-protein, and skin changes: the POEMS syndrome: distinctive radiographic abnormalities. Radiology 1981; 140: 17-22.

6. Iwashita $H$, Ohnishi $A$, Asada $M$, Kanazawa $Y$, Juroiwa $Y$. Polyneuropathy, skin hyperpigmentation, edema and hypertrychosis in localised osteosclerotic myeloma. Neurology 1977; 27: $675-681$.

7. Kelly JJ, Kyle RA, Miles JM, O’Brein PC, Dyck PJ. The spectrum of peripheral neuropathy in myeloma. Neurology 1981; 31: 3134.

8. Kelly JJ, Kyle RA, Miles JM, Dyck PJ. Osteosclerotic myeloma and peripheral neuropathy. Neurology 1983; 33: 202-210.

9. Waldenstorm JG, Adner A, Gydell K, Zettervall O. Osteosclerotic $\sim$ plasmocytoma with polyneuropathy, hypertrichosis, and diabetes. Acta Med Scand 1978; 203: 297-303.

10. Driedger H, Pruzanski W. Plasma cell neoplasia with peripheral polyneuropathy: a study of five cases and a review of the literature. Medicine (Baltimore) 1980; 59: 301-310.
11. Libeert P, Van Hoof A, Louwagie A, Marchau M, Dehaene I. The POEMS-syndrome: an unusual form of plasma cell dyscrasia. Acta Clin Belg 1987; 42: 188-192.

12. Reitan JB, Pape E, Fossa SD, et al. Osteosclerotic myeloma with polyneuropathy. Acta Med Scand 1980; 208: 137-144.

13. Vidakovic A, Simic P, Stojisavljevic N, et al. Polyneuropathy with osteosclerotic myeloma-POEMS syndrome. Neurology 1992; 239: 49-52.

14. Miralles GD, O'Fallon JR, Talley NJ. Plasma-cell dyscrasia with polyneuropathy. The spectrum of POEMS syndrome. N Engl J Med 1992; 327: 1919-1923.

15. Lach B, Rippstein P, Atack D, Afar DEH, Gregor A. Immunoelectron microscopic localization of monoclonal $\lg M$ antibodies in gammopathy associated with peripheral demyelinative neuropathy. Acta Neuropathol 1993; 85: 298-307.

16. Monaco S, Bonetti B, Ferrari S, et al. Complement-mediated demyelination in patients with IgM monoclonal gammopathy and polyneuropathy. N Engl J Med 1990; 322: 649-652.

17. Reulecke M, Dumas M, Meier C. Specific antibody activity against neuroendocrine tissue in a case of POEMS syndrome with IgG gammopathy. Neurology 1988; 38: 614-616.

18. Matsumine $H$. Accelerated conversion of androgen to estrogen in plasma cell dyscrasia associated with polyneuropathy, anasarca, and skin pigmentation. N Engl J Med 1985; 313: $1025-1026$.

19. Shelly WB, Shelly ED. The skin changes in the Crow-Fukase (POEMS) syndrome. Arch Dermatol 1987; 123: 85-87.

20. Ishikawa $O$, Nihei I, Ishikawa $H$. The skin changes of POEMS syndrome. Br J Dermatol 1987; 117: 523-526.

21. Kanitakis J, Roger H, Soubrier M, Dubost JJ, Chouvet B, Souteyrand P. Cutaneous angiomas in POEMS syndrome. Arch Dermatol 1988; 124: 695-698.

22. Trentham DE, Masi AT, Marker HW. Polyneuropathy and anasarca: evidence for a new connective-tissue syndrome and vasculopathic contribution. Ann Intern Med 1976; 84: 271-274.

23. Dyck PJ, Low PA, Windebank AJ, et al. Plasma exchange in polyneuropathy associated with monoclonal gammopathy of undetermined significance. N Engl J Med 1991; 325: I482-1486. 